\title{
Biossegurança e desastres: conceitos, prevenção, saúde pública e manejo de cadáveres
}

| ${ }^{1}$ Telma Abdalla de Oliveira Cardoso, ${ }^{2}$ Fernando Guilherme da Costa,

${ }^{3}$ Marli B. M. de Albuquerque Navarro I

Resumo: O artigo discute a complexidade dos desastres, realçando situações de risco e a essencialidade do suporte da Biossegurança, uma vez que, em episódios com vítimas fatais, os procedimentos formulados por este campo devem ser adotados no manejo de cadáveres, sobretudo quando da ocorrência de soterramento com busca de corpos. Contextualiza a magnitude dos desastres caracterizados pelas chuvas e suas consequências (deslizamentos, soterramento), enfatizando o fenômeno do aquecimento global e as mudanças climáticas e seus impactos sobre as comunidades, em especial as mais pobres, valorizando a análise do conceito de vulnerabilidade a partir do cenário da urbanização, da degradação do meio ambiente causada pelo manejo inadequado dos recursos naturais, da contaminação ambiental, das políticas públicas ineficientes, sublinhando o baixo investimento em infraestrutura. Sublinha o conceito de desastre como fenômeno imprevisível, súbito e violento, que causa grande número de mortos e destruição. Enfatiza as problemáticas sociais, sanitárias, jurídicas e operacionais quando do registro de um número elevado mortes ocorridas ao mesmo tempo ou em curto espaço de tempo. Traz para a análise a contribuição da Biossegurança como orientadora dos planos de emergência voltados para os desastres, realçando o risco biológico e as medidas necessárias para o manejo de cadáveres.

\author{
1 Doutora em Saúde Pública \\ (Escola Nacional de Saúde \\ Pública/Fiocruz); pesquisadora \\ sênior e coordenadora do \\ Núcleo de Biossegurança (ENSP/ \\ Fiocruz). Endereço eletrônico: \\ abdalla@fiocruz.br \\ ${ }^{2}$ Especialista em Biossegurança \\ em Saúde (Instituto de Pesquisa \\ Clínica Evandro Chagas/Fiocruz); \\ chefe nacional de Socorro e \\ Desastres da Cruz Vermelha \\ Brasileira. Endereço eletrônico: \\ costarecue@yahoo.com.br \\ ${ }^{3}$ Doutora em História \\ Contemporânea (Université \\ Paris X); pesquisadora sênior do \\ Núcleo de Biossegurança (ENSP/ \\ Fiocruz). Endereço eletrônico: \\ mnavarro@fiocruz.br
}




\section{Introdução}

Desastres naturais são eventos complexos, cuja compreensão e prevenção dependem da contribuição de vários domínios do conhecimento científico, tais como, Geologia, Climatologia, Meteorologia, Física, Geografia, Sociologia, Ecologia e Saúde Pública, enfim, do conjunto de saberes capazes de analisar a complexidade ambiental. Mais recentemente, a Biossegurança responde à demanda analítica e operacional das questôes ambientais, em especial quando estas se definem como situações de desastres, uma vez que desastres são essencialmente ocorrências que exigem análises voltadas para a prevenção e prospecção, de situações e sequelas. São episódios súbitos e inesperados, e em geral, de gravidade e magnitude expressiva, com importante impacto sobre a sociedade, pois causam danos, traduzidos em prejuízos socioeconômicos, representados de imediato nas perdas materiais e humanas. Pode, ainda, haver a ampliação do risco, através de condições favoráveis para a propagação de doenças, contaminações tóxicas e radioativas, produzindo impactos significativos sobre a saúde pública e o ambiente.

Nesse contexto, a Biossegurança possui elementos práticos e cognitivos para estabelecer açóes preventivas e orientadoras de procedimentos capazes de controlar, atenuar e/ou eliminar tais riscos, especialmente o biológico, considerando que sua matriz construtora se definiu a partir da necessidade de monitoramento e contenção de risco em laboratórios que manipulavam agentes biológicos. Sublinha-se que os desastres são diferenciados principalmente em função de sua origem, isto é, da natureza do fenômeno que o desencadeia, podendo ser naturais, antropogênicos e mistos (BRASIL, 2007; MARCELINO, 2007; TOBIN; MONTZ, 1997).

Estudos sobre a construção de modelos e definições conceituais de desastres registram que, originalmente,

[...] as diferentes abordagens sobre o conceito de desastre poderiam ser agrupadas em três principais paradigmas, quais sejam: o desastre como um agente externo ameaçador; o desastre como expressão social da vulnerabilidade; e, por fim, o desastre como um estado de incertezas geradas pelas próprias instituiçôes (MARCHEZIN, 2009, p. 49).

$\mathrm{Na}$ história da construção do conceito de desastre, o primeiro paradigma propôs a reflexão conceitual adotando como modelo as situações de guerra, onde 
os impactos sobre as comunidades humanas se processam a partir de agentes agressores externos (MARCHEZIN, 2009; GILBERT, 1998). Esta valorização da externalidade das causas do evento gerou, na sociedade, a consolidação da percepção de que os fenômenos externos são determinantes para a configuração do evento. Tomando como exemplo o Brasil, essa percepção é revelada quando das inundações, deslizamentos e soterramentos: são as chuvas que matam que deixam desabrigados (GILBERT, 1998), isentando a participação dos aspectos sociais, relativos sobretudo à ocupação e uso do espaço territorial.

Enrico Quarantelli (1998) relata a ausência de consenso, na Sociologia, sobre o que é nomeado como desastre, sendo possível entendê-lo como um misto de construção social e acontecimento físico, isto é, uma elaboração cultural para lidar com açôes e omissões humanas causadoras de danos intensos, que têm concentração espaço-temporal. Esta abordagem relativizou as causas externas dos agentes destrutivos na configuração dos desastres e trouxe para a discussão conceitual a participação e o reconhecimento do campo das Ciências Sociais, legitimando-o para as análises dos fatores de risco que desencadeiam os desastres e, por conseguinte, para a prevenção dos mesmos.

As Ciências Sociais ganharam importância como instrumento para a compreensão da complexidade dos desastres, propostos pela Sociologia, a partir dos debates de Ulrich Beck. Este autor, em sua obra Ecological enlightenment: essays on the politics of the risk society (1995), descreveu e analisou os riscos como centrais e constitutivos da sociedade, que se moderniza incessantemente, expressando o conceito de sociedade de risco, associado à análise dos efeitos deletérios da sociedade moderna, como sequelas que estão representadas nos riscos sociais, políticos, econômicos e individuais.

Marchezin (2009, p. 50), a partir das discussões da teoria da sociedade de risco de Beck, demonstrou que "esta teoria desloca a ideia do perigo e do risco como eventos excepcionais para sua compreensão na própria estrutura social, ou seja, os riscos produzidos na e pela modernidade são fabricados socialmente, procedem da incisiva intervenção humana sobre o meio". Esse autor introduz então a noção de que os desastres devam ser compreendidos como um processo ligado à vulnerabilidade social e que a natureza dos desastres está ligada à organização social e suas causas devem ser explicadas como problemas estruturais, devendo ser contextualizadas. 
Um aspecto comum destas discussões é que tanto as Ciências Sociais, quanto a Sociologia, compreendem os desastres "ditos naturais", não como variáveis independentes e intrinsecamente relacionados somente aos fenômenos naturais, mas em um âmbito multidimensional e multiescalar, focados na estrutura e na dinâmica social, o que possibilita múltiplas interpretações acerca das relações sociais, territoriais, institucionais e historicamente produzidas (VALENCIO, 2009a). Esta perspectiva privilegia e conjuga múltiplos saberes para o entendimento dos desastres, em especial aqueles que configuram o desencadeamento de outros contextos de risco, como por exemplo, a propagação de doenças e a contaminação ambiental, exigindo a participação da Biossegurança como propositora de conhecimento e formuladora de ações preventivas.

\section{A dimensão da complexidade dos desastres}

Embora os desastres ocorram em todos os continentes, é certo que eles causam maiores impactos e danos mais expressivos nos países pobres dos que nos países em desenvolvimento. "A pobreza e miséria estruturais e a insuficiência das ações do Estado e fragilidade institucional para refreá-las são os elementos adicionais para eliminar a possibilidade de redução de desastres ou mitigação das perdas" (VALENCIO, 2009b, p.227).

Fatores culturais e afetivos também estão no âmbito da complexidade dos desastres. A ocupação do espaço territorial cria modos de vida, define cotidianos, estabelece relaçôes de afeto, cristaliza identidade e lugar, estabelecendo questôes que dificultam o encaminhamento de propostas mais práticas e imediatas, como, por exemplo, a remoção de populações de áreas consideradas de risco.

Sublinha-se que a questão da justiça ambiental confere à análise sobre desastres uma real complexidade, pois muitas vezes

[...] a remoção das moradias é tratada como uma discussão meramente paisagística muito embora subjacente ao núcleo residencial haja, para o grupo ali inserido, sentidos de pertencimento, necessidades, sociabilidades espacializadas. Do outro lado, as fraturas do território dos ricos são compensadas com medidas céleres de recomposição das funcionalidades do espaço, o poder público tomando medidas de abastecimento hídrico, drenagem urbana e afins para que estes possam se reerguer no lugar que consideram seu e são reconhecidos pelo ente público como tal. Um aspecto complementar das injustiças ambientais, que os desastres revelam, é a compaixão e a solidariedade macroenvolventes com o sofrimento dos grupos étnicos de ascendência europeia e a 
indiferença frente ao sofrimento social de negros, nordestinos, caboclos, indígenas,

migrantes precarizados que, no país adentro, vivenciam inundaçôes, enxurradas, deslizamentos, secas prolongadas, sem causar comoção social (VALENCIO, 2009a, p.7).

Destaca-se igualmente que a temática da justiça ambiental alcança a discussão que relaciona desastres, saúde pública, risco e vulnerabilidade de populações, uma vez que tais eventos, em geral, provocam enchentes, escorregamentos, soterramentos e outros impactos capazes de produzir condiçōes favoráveis a contaminação de pessoas, proliferação de vetores e comprometimento do meio ambiente. Estas condiçōes podem se exacerbar quando se verifica grande número de mortos, que muitas vezes esgota a capacidade local no atendimento emergencial, considerando também como situação de risco a existência de cadáveres soterrados, cujo resgate pode demandar dias ou semanas.

\section{Desastres, vítimas, saúde pública e risco}

O banco de dados Emergency Events Database (EM-DAT), mantido pela Organização Mundial da Saúde (OMS), aponta que entre 1900-2010, o maior número de desastres de características naturais e/ou antropogênicas no mundo ocorreu no continente asiático. Dentre esses desastres, os mais frequentes são as inundações $(35 \%)$ e as tempestades (31\%), que são, muitas vezes, resultantes de eventos como furacōes, tornados e vendavais (WHO, 2011). Além disto, é importante ressaltar que a maioria dos desastres (mais de 70\%) ocorreu em países em desenvolvimento, refletindo as condiçôes de vulnerabilidade de suas populações, pelas situaçooes socioeconômicas em que se encontram, contribuindo, de forma significativa, para elevar o número de vítimas fatais. Sublinha-se que esta vulnerabilidade traduz a susceptibilidade de indivíduos ou grupos que estão inseridos em ambientes hostis ou bastante degradados. Deve-se, no entanto, observar que os estudos, sobre a susceptibilidade ambiental e humana em territórios favorecedores de desastres demonstram a dependência da percepção do meio sócio-ecológico para a redução da vulnerabilidade, especialmente na orientação do gerenciamento de risco como instrumento de governança, o que inclui, necessariamente, democratização de acesso a meios materiais e tecnológicos na proteção das adversidades que os fenômenos climáticos poderão impor (VALENCIO et al., 2009). 
A tabela 1 apresenta os tipos de desastres naturais ocorridos no mundo, no período compreendido entre 1970 a janeiro de 2010 e que ocasionaram mortes acima de 1.000 pessoas (GOYET, 2004; MORGAN; GOYET, 2005; WORLD DISASTERS TIMELINE, 2009).

No Brasil, os desastres naturais mais frequentes, apontados pelo Ministério da Saúde, foram: as inundaçôes, representadas pelas graduais e bruscas, com $59 \%$ dos registros; seguidas pelos escorregamentos ou deslizamentos de terra (14\%). Mais de $80 \%$ dos desastres estão associados às instabilidades atmosféricas severas, que são responsáveis pelo desencadeamento de inundações, vendavais, tornados, granizos e escorregamentos. As regiōes mais afetadas foram Sudeste, Sul, Nordeste, Norte e Centro-Oeste, respectivamente (BRASIL, 2007).

Tabela 1. Desastres naturais ocorridos entre 1970 a 2010*, com mortes acima de mil pessoas

\begin{tabular}{|c|c|c|c|}
\hline Ano & Local & Tipo de desastre & $\mathrm{N}^{0}$ de mortos \\
\hline $2010^{*}$ & Haiti & Terremoto & 150.000 \\
\hline 2009 & Indonésia & Terremoto & 5.000 \\
\hline \multirow[t]{2}{*}{2008} & China & Terremoto & 50.000 \\
\hline & Ásia & Vendaval & 78.000 \\
\hline 2007 & Bangladesh & Furacão & 3.500 \\
\hline \multirow[t]{2}{*}{2006} & Filipinas & Deslizamento & 1.500 \\
\hline & Indonésia & Terremoto & 6.000 \\
\hline \multirow[t]{3}{*}{2005} & Índia & Enchente & 1.000 \\
\hline & EUA & Furacão (Katrina) & 1.826 \\
\hline & Paquistão & Terremoto & 18.000 \\
\hline \multirow[t]{4}{*}{2004} & Haiti & Enchente & 1.000 \\
\hline & República Dominicana & Enchente & 2.000 \\
\hline & Indonésia & Terremoto/ Tsunami & 212.000 \\
\hline & Irã & Terremoto & 28.000 \\
\hline
\end{tabular}




\begin{tabular}{|c|c|c|c|}
\hline \multirow[t]{3}{*}{2003} & Argélia & Terremoto & 2.000 \\
\hline & França & Calor excessivo & 3.000 \\
\hline & Irã & Terremoto & 28.000 \\
\hline 2002 & Afganistão & Terremoto & 2.000 \\
\hline \multirow[t]{2}{*}{2001} & El Salvador & Terremoto & 1.159 \\
\hline & India & Terremoto & 30.000 \\
\hline \multirow[t]{2}{*}{1999} & Colômbia & Terremoto & 1.186 \\
\hline & Venezuela & Enchente & 33.989 \\
\hline \multirow[t]{2}{*}{1998} & México & Enchente & 1.256 \\
\hline & América Central & Furacão (George e Mitch) & 21.865 \\
\hline 1994 & Haiti & Temporal & 1.122 \\
\hline 1987 & Equador & Terremoto & 4.000 \\
\hline \multirow[t]{2}{*}{1985} & México & Terremoto & 8.776 \\
\hline & Colômbia & Erupção vulcão & 21.800 \\
\hline 1979 & República Dominicana & Furacão & 1.400 \\
\hline 1976 & Guatemala & Terremoto & 23.000 \\
\hline 1972 & Nicarágua & Terremoto & 10.000 \\
\hline 1970 & Peru & Terremoto & 73.000 \\
\hline
\end{tabular}

* até janeiro de 2010

Fonte: Adaptado pelos autores de Goyet, 2004; Morgan; Goyet, 2005; World Disasters Timeline, 2009. 
Segundo dados do EM-DAT (2011), houve aumento na incidência de eventos climáticos com temperaturas extremas e enchentes, no território brasileiro, no período compreendido entre 1970 e 2008, causando a morte de mais de 6 mil pessoas e prejuízos da ordem de 10 bilhôes de dólares (tabela 2). O furacão Catarina, por exemplo, em março de 2004, atingiu 26 municípios dos estados de Rio Grande do Sul e Santa Catarina, deixando 15 mil pessoas desabrigadas e 11 mortos (WHO, 2006). A importância desse tema se destaca diante das inundações e deslizamentos ocorridos em janeiro de 2011 na região serrana do Estado do Rio de Janeiro, atingindo 18 municípios. Levantamentos provisórios informavam que, até a data mencionada, em torno de 95.000 pessoas haviam sido atingidas, com 10.484 desabrigados, 24.198 desalojados e 916 óbitos (WHO, 2011).

Tabela 2. Ocorrência de desastres naturais no Brasil no intervalo entre 1970 e 2008, número de mortos e prejuízos causados

\begin{tabular}{llllll}
\hline \multicolumn{1}{c}{ Período } & \multicolumn{5}{c}{ Evento climático } \\
\cline { 2 - 6 } 1970 a 2008 & Estiagens & Epidemias & $\begin{array}{c}\text { Temperaturas } \\
\text { extremas }\end{array}$ & Enchentes & $\begin{array}{c}\text { Total no } \\
\text { período }\end{array}$ \\
\hline $\begin{array}{l}\text { Total por ocorrência } \\
\text { climática }\end{array}$ & 15 & 14 & 6 & 79 & 114 \\
$\begin{array}{l}\text { Total de mortos } \\
\text { Prejuízo (US\$) }\end{array}$ & 20 & 2138 & 210 & 3.747 & 6.115 \\
\hline
\end{tabular}

Fonte: Adaptado pelos autores de WHO, 2011; World Disasters Timeline, 2009.

Imediatamente após a ocorrência de um desastre, as autoridades do país, sejam nacionais, regionais ou municipais, devem focar suas ações e recursos em três atividades básicas: a) resgate e atenção aos sobreviventes; b) reabilitação e manutenção e recuperação dos serviços básicos; e c) manejo e disposição de cadáveres.

Ressalta-se que a maioria dos desastres, com exceção das inundações graduais, são fenômenos imprevisíveis, súbitos e violentos, que causam grande número de mortos e destruição, pois não permitem que as pessoas procurem abrigos ou salvem parte dos bens existentes em suas casas. A prioridade está precisamente na atenção aos sobreviventes e à manutenção dos serviços básicos, porém não podemos ignorar a disposição dos cadáveres. Sem dúvida nenhuma, o manejo de 
um elevado número de mortes ocorridas ao mesmo tempo ou dentro de curto espaço de tempo representa um problema social, sanitário, jurídico e organizativo.

O desastre pode ocorrer em uma zona de difícil acesso ou em um meio aquático, requerendo pessoal técnico especializado e determinados instrumentos. Pode haver, ainda, situações em que o atendimento aos feridos e o recolhimento de cadáveres facilmente excedem a capacidade operativa, de materiais ou de pessoal, constituindo assim uma situação crítica dentro do desastre. Por esta razão, os planos de emergência aos desastres, independentemente de sua origem, devem conter as medidas a serem tomadas em relação ao manejo de cadáveres ou fragmentos cadavéricos, basicamente integrados ao translado, identificação, armazenamento e conservação (em caso de necessidade) e disposição final. Para a elaboração dos planos de emergência, é necessário incluir os princípios de Biossegurança, visando reduzir os riscos, descrevendo princípios de contenção, equipamentos de segurança, técnicas e práticas, a fim de assegurar a saúde dos profissionais envolvidos no atendimento emergencial, prevenindo a exposição acidental aos agentes de risco e a saúde pública. Sendo assim, situações que se configuram como risco estão no domínio da Biossegurança, campo este que deve implementar estratégias de proteção baseadas na avaliação de risco. É a análise da dimensão e da potencialidade do risco que irá determinar a estratégia da ação preventiva. A avaliação de riscos é a ferramenta que possibilita essa análise e, a partir dela, a escolha das ações que irão orientar a tomada de decisão.

\section{Manejo de cadáveres e o risco biológico associado}

Manejo de cadáveres é um tema que está envolto em mitos que rodeiam seu tratamento, onde está arraigada fortemente a cultura das populaçóes. As mortes associadas aos desastres naturais são normalmente causadas por traumas, afogamentos, queimaduras, entre outros. A presença súbita de um aumento no número de cadáveres, nas áreas afetadas por desastres, pode ocasionar temor na população de ocorrência de surtos de doenças, porém não há evidências que a presença de cadáveres represente risco de aumento no surgimento de epidemias na área do desastre (WHO, 2006).

Para que ocorra a transmissão de uma infecção, é necessária a presença de um agente infeccioso, exposição a este agente e um hospedeiro susceptível. O corpo humano é hospedeiro de vários agentes biológicos, alguns dos quais patogênicos, 
no entanto, a maioria não sobrevive mais que 48 horas no corpo humano após a morte e é neste período que há maior risco de ocorrência de infecções pelo manejo inadequado. Porém, na avaliação do risco, que deve ser efetuada para o manejo correto dos cadáveres, é necessário considerar os elementos que determinam a transmissão. Os cadáveres só representarão riscos em algumas situações que requerem precauções específicas, tais como mortes ocasionadas por cólera ou por febre hemorrágica. É possível que algumas vítimas possam ser portadoras de infecções e exigirão, portanto, cuidados especiais. Observa-se, porém, que os agentes biológicos envolvidos no processo de putrefação natural não são patogênicos (WHO, 2006; MORGAN, 2004; WHO, 2004; GOYET, 1980).

As vítimas de desastres albergam patógenos que estão circulando na população local, assim o risco é similar ao manejo de pacientes nas áreas de assistência à saúde. Além disso, a maioria dos agentes não é capaz de sobreviver por longos períodos nos corpos, como apontado anteriormente e, portanto, os sobreviventes representam o reservatório de doenças infecciosas mais importante (MORGAN, 2004).

Estudos demonstram que a contaminação das fontes de água para consumo por cadáveres após os desastres naturais são as causas principais do aumento de doenças gastrointestinais. Estudo conduzido por Campanella (1999) no município de Villanueva/Nicarágua, por três meses após o furacão Mitch, em 1998, mostrou que a incidência de diarreias agudas e de doenças respiratórias agudas teve aumento significativo após o desastre. A incidência de diarreias agudas passou de 2.849 a 6.798 casos por 100.000 habitantes após o furacão $(\mathrm{P}<0.01)$, enquanto que a incidência de doenças respiratórias agudas elevou-se de 295 para 1.205 casos por 100.000 habitantes $(\mathrm{P}<0.01)$ (CAMPANELLA, 1999). E um cluster de infecções por hepatite A que ocorreu na província de Aceh, Indonésia, no mês seguinte ao tsunami de 2004, foi associado à presença de corpos, contaminando as fontes de água potável (WHO, 2005).

Os desastres com um grande número de mortes requerem uma força-tarefa para a coleta, transporte, armazenamento, conservação, quando necessário, e disposição final dos corpos. Este trabalho é normalmente executado por militares, profissionais de atendimento emergencial e de sobrevivência, voluntários e outros que possuem escassa ou nenhuma formação ou experiência. 
Existem poucos artigos publicados a respeito do risco a que estão sujeitos este grupo de profissionais, mas o risco é similar ao enfrentado pelos profissionais de saúde, de funerárias e de necrotérios (BOAL et al., 2005; RISCHETELLI et al., 2001; CDC, 2000; GERSHON et al., 1998; HEALING et al., 1995; GERSHON et al., 1995; GOYET, 1980).

Os agentes biológicos causadores de doenças infecciosas associadas ao manejo de cadáveres estão apresentados no quadro 1 (WHO, 2006; CONLY; JOHNSTON, 2005; MORGAN, 2004; HEALING et al., 1995; GOYET, 1980).

Quadro 1. Agente biológico causador de doenças infecciosas associadas ao manejo de cadáveres após desastres naturais

\begin{tabular}{ll}
\hline Transmissão & Agente biológico \\
\hline Sangue & Vírus da Hepatite B \\
Vírus da Hepatite C \\
Vírus HIV \\
Vírus HTLV \\
Rotavirus \\
Campylobacter enteritis \\
Salmonella \\
Yersinia \\
Vibrio cholerae \\
Vibrio vulnificus \\
Escherichia coli \\
Vírus da Hepatite A \\
Shigella \\
Leptospira \\
Norovírus \\
Adenovirus entéricos \\
Giardia \\
Cryptosporidium \\
M. tuberculosis \\
Fespiratória & WhO, 2006; Conly; \\
\hline
\end{tabular}

Fonte: Adaptado pelos autores de WHO, 2006; Conly; Johnston, 2005; Morgan, 2004; Healing et al., 1995; Goyet, 1980. 
Estudos demonstram que o risco de transmissão de doenças pelo sangue ocorre como resultado de ferimentos percutâneos ocupacionais ou através de respingos de sangue nas membranas mucosas, e vai depender do potencial de risco infeccioso que a vítima pode representar. Ressalta-se que o vírus da imunodeficiência humana continua viável no sangue e nos fluidos pleural e do pericárdio de cadáveres até $16 \frac{1}{1 / 2}$ dias, se o corpo estiver estocado a baixas temperaturas $\left(2^{\circ} \mathrm{C}\right)$ (CONLY; JOHNSTON, 2005; DEMIRYÜREK et al., 2002). Nyberg et al. (1990) isolaram o HIV em fragmentos ósseos, baço, cérebro, medula óssea e nódulos linfáticos na autópsia de um paciente após seis dias de postmortem. Em 2006, a Organização Mundial da Saúde relatou a presença do HIV em cadáveres seis dias após o tsunami ocorrido na Indonésia (WHO, 2006).

Exames de sangue feitos nos bancos de doação de órgãos, com marcadores sorológicos para hepatite, detectaram uma taxa de 18,1\% para hepatite B e de 14,3\% para hepatite C (DEMIRYÜREK et al., 2002; BARNETT et al., 2001; WATKINS et al., 1998; ROTH et al., 1992). A alta taxa de prevalência de HIV e de hepatite $\mathrm{B}$ em estudos sorológicos em cadáveres demonstra que órgãos de doadores podem transmitir estas infecções (DEMIRYÜREK et al., 2002; CATTANEO et al., 1999; LUTWICK et al., 1983). Os cadáveres eliminam frequentemente excrementos durante a manipulação, representando risco de exposição aos agentes biológicos causadores de doenças gastroentéricas. O contato pode ocorrer de forma direta ou indireta, através da contaminação das vestimentas, macas, sacos para coleta de cadáveres (sacos morgues) e veículos transportadores. Entretanto, ressalta-se que os agentes biológicos mais comuns envolvidos nestas infecções não sobrevivem por longos períodos no ambiente.

A reemergência da tuberculose nos países desenvolvidos e o agravamento da situação nos países em desenvolvimento levaram a OMS a declarar a tuberculose, em seu relatório anual de abril de 1993, uma "emergência global" (ALMEIDA et al., 2005). A transmissão do M. tuberculosis pode ocorrer por exposição aos bacilos infecciosos aerolizados. O bacilo de Koch permanece viável por grandes períodos de tempo em cadáveres e a oportunidade de aerolização durante o manejo é bastante grande, demonstrando o risco de exposição entre os profissionais que os manipulam (CONLY; JOHNSTON, 2005; DEMIRYÜREK et al., 2002; GERSHON et al., 1998; MCKENNA et al., 1996). A transmissão pode ocorrer através da exposição aos fluidos e/ou ar expulsos, pelo trato respiratório no 
processo de putrefação ou quando o ar residual dos pulmões é eliminado durante

o manejo dos corpos. Além disso, o armazenamento de muitos corpos em locais temporários amplifica este risco.

\section{Medidas de Biossegurança para reduzir o risco}

Durante as situações de desastres, torna-se imperativo conscientizar os profissionais sobre a importância dos princípios de Biossegurança. A observância das precauções universais e o uso de procedimentos de segurança específicos, aliados aos equipamentos de contenção adequados, minimizam o risco de exposição e, por conseguinte, infecção associada ao manejo de cadáveres, além de contribuírem para evitar a contaminação ambiental. Estes elementos são chamados de barreiras de contenção.

No primeiro momento, a recuperação de corpos é caótica e desorganizada. Esta atividade não deve interromper a execução dos trabalhos que visam à ajuda imediata aos sobreviventes, mas é uma fase importante para a identificação dos mortos e reduz a carga psicológica dos sobreviventes. A remoção dos corpos, da área afetada, deve ocorrer rapidamente, sempre que possível, seguindo-se à identificação. Deve-se respeito aos mortos, assim como às crenças, costumes sociais, culturais e religiosos locais.

O enterro é preferível à cremação, pois há a possibilidade de preservar evidências para futuras investigações. Enterros em massa devem ser evitados. A opção por cremação será feita quando não há mais condições de identificação dos corpos. Como a queima completa dos corpos é difícil, os restos mortais deverão ser enterrados. Muitas vezes essas operações são inviabilizadas por haver necessidade de grandes quantidades de produtos químicos combustíveis. A cremação de um grande número de cadáveres é complexa, pois é difícil a logística e a organização.

Em casos de sepultamento em massa, as covas devem possuir no mínimo 1,5m de profundidade e com uma distância de $200 \mathrm{~m}$ das fontes de captação de água de consumo. Não se recomenda ultrapassar $3 \mathrm{~m}$ de profundidade, para não atingir o lençol freático, mas também se deve evitar as covas rasas. As covas deverão ser numeradas e marcadas com dados de identificação, além de serem colocadas em um mapa de localização. Todos os esforços devem ser feitos para a identificação dos corpos. Dados como locais exatos e a data onde foram encontrados os corpos devem ser anotados, pois estas informações irão constituir elementos para futura 
identificação. Os pertences pessoais, joias e documentos não devem ser retirados dos corpos, a fim de facilitar a identificação (no primeiro momento). Os corpos deverão receber uma etiqueta contendo informações da pessoa. Após a fase de identificação, esses pertences serão entregues aos parentes mais próximos.

Em regiōes quentes, a decomposição dos cadáveres ocorre entre 12 e 48 horas, tornando difícil a identificação pelo rosto da vítima. $\mathrm{O}$ armazenamento dos cadáveres em frio diminui a velocidade de decomposição e preserva o corpo para a identificação. Os corpos devem ser mantidos inicialmente em sacos de cadáveres, principalmente aqueles que possuem muitos danos. Ressalta-se que os sacos morgues dificultam o resfriamento, assim como aumentam a taxa de decomposição dos corpos em regiôes quentes. $\mathrm{Na}$ falta destes sacos, podem ser utilizados outros recursos, como plásticos. Peças anatômicas devem ser tratadas como cadáveres.

A retirada de cadáveres de espaços confinados sem ventilação deve ser feita com cuidado, pois após vários dias de decomposição pode haver a presença de gases tóxicos potencialmente perigosos, como o gás metano (LEWIS, 2008). Para o transporte, os corpos deverão ser cobertos, e permanecerão assim até serem enterrados. Deve-se evitar o uso de ambulâncias, deixando este transporte preferencialmente para os feridos.

As precauções universais para o manuseio de materiais biológicos, tais como sangue e fluidos corporais, devem ser seguidas. A higiene básica é uma grande aliada para proteção nos trabalhos. Lavar frequentemente as mãos e sempre após o manuseio dos corpos. Recomenda-se o uso de vestimenta protetora, composta de calça e blusão de mangas compridas ou macacão confeccionado em polietileno, do tipo tyvek, descartáveis, por cima do vestuário. É obrigatória a utilização de sapatos fechados ou botas e luvas. A utilização de luvas especiais, como as resistentes à punctura (nitrílicas ou metálicas) ou as específicas para determinadas substâncias químicas, deverá ser estabelecida na avaliação de risco. Máscaras descartáveis com filtração (PFF 2 ou bico de pato ou N95) deverão ser utilizadas para proteção respiratória de agentes biológicos com risco de aerolização. O risco de aerolização de patógenos do trato respiratório de cadáveres é diminuído ao colocar um pano sobre a boca do cadáver e pela ventilação adequada nos locais de armazenamento (MORGAN, 2004; DEMIRYÜREK et al., 2002). Óculos de segurança ou protetores faciais completos deverão ser utilizados para proteção das 
mucosas e olhos contra impactos de partículas volantes, respingos de produtos químicos e espirros de sangue e fluidos corpóreos.

Os equipamentos de proteção individual descartáveis deverão ser descartados como resíduos do grupo A ("resíduos biológicos"). Todos os equipamentos e instrumentos, incluindo macas e veículos de transporte deverão ser descontaminados e lavados. Cadáveres não necessitam de desinfecção antes de manuseio (com exceção nos casos de cólera ou febre hemorrágica).

A área de armazenamento temporária dos corpos deve ser em um local amplo, bem ventilado e protegido das intempéries climáticas. Deve ser dividido em três áreas: recepção, exposição e armazenamento dos corpos. Os Institutos de Medicina Legal são os locais mais adequados ao armazenamento, mas frequentemente são insuficientes ou não estão próximos às áreas atingidas pelo desastre. Lugares como estádios esportivos têm sido utilizados como áreas de armazenamento temporário.

Devido ao alto risco de infecção pelos agentes causais da hepatite B, difteria, tétano, HIV e tuberculose, recomenda-se que as equipes envolvidas iniciem um esquema completo de vacinação estabelecido para cada vacina (CDC, 2000). A vacina $B C G$ produz alguma proteção contra a tuberculose e testes tuberculínicos devem ser aplicados após a vacinação (MORGAN, 2004; STERLING et al., 1999). É necessária atenção redobrada com os profissionais não vacinados contra o tétano, pois durante a execução dos trabalhos há o risco de ferimentos e de infecção pelo Clostridium tetani.

Cuidados especiais devem ser tomados no manuseio de materiais perfurocortantes, como instrumentais cirúrgicos utilizados na preparação dos cadáveres, tais como pinças, tesouras, lâminas de bisturis, agulhas e equipamentos de injeção e extração de líquidos. Os acidentes ocasionados por picada de agulhas são responsáveis por 80 a $90 \%$ das transmissões de doenças infecciosas entre trabalhadores de saúde (CDC, 2000), mas também ocorrem em outros serviços de assistência à saúde, como instituiçôes de longa permanência para idosos, serviços de atendimento domiciliar (home care) e serviços de atendimento de emergência.

As precauções universais estabelecem conceitos importantes e são uma abordagem com eficácia demonstrada para a prevenção de exposiçôes cutâneas e de mucosas (CDC, 2000). O controle do comportamento e das atitudes individuais, exemplificado pelo uso de equipamentos de proteção individual e 
por mudanças nas práticas de trabalho de cada indivíduo, como a utilização de coletores rígidos para descarte e evitar-se o reencape, auxiliam na redução da incidência de acidentes com matérias perfurocortantes.

Nos desastres ocorre também a morte de animais. Algumas medidas essenciais deverão ser tomadas, das quais se destaca a incineração das carcaças que deverão ser borrifadas com produto químico inflamável, como gasolina, com objetivo de evitar a proliferação de vetores e microrganismos. Os animais vivos deverão ser capturados e serem alojados em instalações específicas. Os serviços veterinários deverão monitorar as possíveis doenças zoonóticas transmissíveis, realizar vacinação em massa nos rebanhos locais, sacrificar animais doentes, isolar as propriedades rurais afetadas por doenças e as condições sanitárias do abate de animais para consumo humano. Ressalta-se que a profilaxia animal a ser implementada na região afetada pelo desastre (por ex. vacinação contra raiva, febre aftosa) será orientada pela avaliação de risco.

\section{Considerações finais}

Conceitualmente, os desastres devem ser entendidos a partir das abordagens complexas, contemplando um amplo diálogo com múltiplos campos do conhecimento, incluindo o campo da Biossegurança, especialmente, para operacionalizar procedimentos voltados a mitigar riscos de contaminação, contribuindo assim para procedimentos preventivos voltados para a saúde pública.

Embora não haja evidências de que a presença de cadáveres represente risco de aumento no surgimento de epidemias na área do desastre, a perspectiva da prevenção se estabelece, pois as vítimas de desastres albergam patógenos que estão circulando na população local. Portanto, o risco dos profissionais que manejam os corpos após os desastres é similar ao dos profissionais da saúde, podendo estar expostos aos agentes biológicos causadores de doenças veiculadas através do sangue, de infecções gastrointestinais e de tuberculose.

Medidas simples como a lavagem de mãos, procedimentos básicos de higiene, cuidados na manipulação de materiais perfurocortantes e utilização adequada de equipamentos de proteção são capazes de reduzir o risco ocupacional. É importante para os profissionais, militares ou civis, envolvidos no atendimento emergencial, o estabelecimento de um programa de vacinação e de educação continuada que fazem parte do processo de preparação e de mitigação de desastres. ${ }^{12}$ 


\section{Referências}

ALMEIDA, E.A. et al. Rendimento da cultura de escarro na comparação de um sistema de diagnóstico automatizado com o meio de Lowenstein-Jensen para o diagnóstico da tuberculose pulmonar. J Bras Pneumol, v. 31, n. 3, p. 231-6, 2005.

BARNETT, J.R. et al. Cadaver donor discards secondary to serology. J Burn Care Rehabil, v. 22, n. 2, p. 124-7, 2001.

BECK, U. Ecological Enlightenment. Essays on the politics of the Risk Society. Translated by Mark A. Ritter. New York: Humanity Books, 1995.

BOAL, W.L.; HALES, T.; ROSS, C.S. Blood-Borne Pathogens among Firefighters and Emergency Medical Technicians. Prehospital Emergency Care, v. 9, n. 2, p. 236-47, 2005.

BRASIL. Ministério da Saúde. Secretaria de Vigilância em Saúde. VIGIDESASTRES. Programa Nacional de Vigilância em Saúde Ambiental dos Riscos Decorrentes dos Desastres Naturais. Brasília: Ministério da Saúde, 2007.

CAMPANELLA, N. Infectious diseases and natural disasters: The effects of Hurricane Mitch over Villanueva municipal area, Nicaragua. Public Health Rev, v. 27, n. 4, p. 311-9, 1999.

CATTANEO, C. et al. Prevalence of HIV and hepatitis C markers among a cadaver population in Milan. J Clin Pathol, v. 52, n. 4, p. 267-70, 1999.

CENTERS FOR DISEASE CONTROL AND PREVENTION. Hepatitis C virus infection among firefighters, emergency medical technicians, and paramedics. $M M W R$ Morb Mortal Wkly Rep,. v. 49, n. 29, p. 660-5, 2000.

CONLY, J.M.; JOHNSTON, B.L. Natural disasters, corpses and the risk of infectious diseases. Can J Infect Dis Med Microbiol, v. 16, n. 5, p. 269-70, 2005.

DEMIRYÜREK, D.; BAYRAMOGLU, A.; USTACELEBI, S. Infective Agents in Fixed Human Cadavers: A Brief Review and Suggested Guidelines. The Anatomical Record (New Anat.), v. 269, n. 4, p. 194-7, 2002.

GERSHON, R.R. et al. Occupational risk of human immunodeficiency virus, hepatitis $\mathrm{B}$ virus, and hepatitis $\mathrm{C}$ virus infections among funeral service practitioners in Maryland. Infect Control Hosp Epidemiol., v. 16, n. 4, p. 194-7, 1995.

GERSHON, R.R. et al. Tuberculosis risk in funeral home employees. J Occup Environ Med., v. 40, n. 5, p. 497-503, 1998.

GILBERT, C. Studying disaster: changes in the main conceptual tools. In: QUARENTELLI, E.L. (Ed.) What is a disaster? Perspectives on the question. Routledge: London, 1998. p. 11-18. GOYET, V. C. Epidemics caused by dead bodies: a disaster myth that does not want to die. Rev Panam Salud Publica, v. 15, n. 5, p. 297-9, 2004.

GOYET, V. C. Las enfermedades transmisibles y la vigilancia epidemiológica en situaciones de desastres naturales. Bol Oficina Sanit Panam., v. 89, n. 4, p. 353-9, 1980. 
HEALING, T.D.; HOFFMAN, P.N.; YOUNG, S.E. The infectious hazards of human cadavers. Commun Dis Rep CDR Rev., v. 5, n. 5, p. R61-8, 1995.

LEWIS, T. Infection control policy for the care of the cadaver. London: NHS Great Yarmouth and Waveney, 2008.

LUTWSICK, L.I. et al. The transmission of hepatitis B by renal transplantation. Clin Nephrol, v. 19, n. 6, p. 317-9, 1983.

MARCELINO, E.V. Desastres naturais e geotecnologias: conceitos básicos. Santa Maria: Instituto Nacional de Pesquisas Espaciais, 2007.

MARCHEZIN, V. Dos Desastres da Natureza à Natureza dos Desastres. In: VALENCIO, N. et al. (Orgs). Sociologia dos desastres: construção, interfaces e perspectivas no Brasil. São Carlos: RiMa, 2009. p.48-57.

MCKENNA, M.T. et al. The association between occupation and tuberculosis. A population based survey. Am J Respir Crit Care Med, v. 154, n. 3, Pt 1, p. 587-93, 1996.

MORGAN, O. Infectious disease risks from dead bodies following natural disasters. Pan Am J Public Health, v. 15, n. 5, p. 307-12, 2004.

MORGAN, O.; GOYET, C.V. Dispelling disaster myths about dead bodies and disease: the role of scientific evidence and the media. Rev Panam Salud Publica, v. 18, n. 1, p. 33-6, 2005.

NYRBERG, M.; SUNI, J.; HALTIA, M. Isolation of human immunodeficiency virus infection in health care workers. Arch Intern Med, v. 153, n. 1, p. 1451-8, 1990.

QUARENTELLI, E.L. Introduction: the basic question, its importance, and how it is addresses in this volume. In: QUARENTELLI, E.L. (Ed.) What is a disaster? Perspective on the question. Routledge: London and New York, 1998. p. 1-8.

RISCHETELLI, G. et al. The risk of acquiring hepatitis B or C among public safety workers. Am J Prev Med., v. 20, n. 4, p. 299-306, 2001.

ROTH, D. et al. Detection of hepatitis $\mathrm{C}$ virus infection among cadaver organ donors: Evidence for low transmission of disease. Ann Intern Med, v. 117, n. 6, p. 470-5, 1992.

STERLING, T.R. et al. Tuberculosis vaccination versus isoniazid preventive therapy: A decision analysis to determine the preferred strategy of tuberculosis prevention in HIVinfected adults in the developing world. Int J Tuberc Lung Dis, v. 3, n. 3, p. 248-54, 1999.

TOBIN, G.A.; MONTZ, B.E. Natural Hazards: explanation and integration. New York: The Guilford Press, 1997.

VALENCIO, N. Da Morte da Quimera à Procura de Pégaso. A importância da interpretação sociológica na análise do fenômeno denominado desastre. In: VALENCIO, N. et al. (Orgs). Sociologia dos desastres: construção, interfaces e perspectivas no Brasil. São Carlos: RiMa, 2009a. p.3-18. 
VALENCIO, N. Defesa Civil num Contexto Multiétnico e Multirreligioso: uma contribuição sociológica nos caminhos para a assistência humanitária em Guiné Bissau. VALENCIO, N. et al. (Orgs). Sociologia dos desastres: construção, interfaces e perspectivas no Brasil. São Carlos: RiMa, 2009b. p.227-235.

VALENCIO, N.; SIENA, M.; MARCHEZINI, V. Maquetes Interativas: fundamentos teóricos, metodológicos e experiências de aplicação. In: VALENCIO, N. et al. (Orgs). Sociologia dos desastres: construção, interfaces e perspectivas no Brasil. São Carlos: RiMa, 2009. p. 199-215.

WATKINS, B.P. et al. Postmortem blood tests for HIV, HBV and HCV in a body donation program. Clin Anat., v. 11, n. 4, p. 250-2, 1998.

WORLD DISASTERS TIMELINE. Major Events in 21 st Century Disasters. Disponível em: <http://www.mapreport.com/subtopics/d.html> Acesso em: 1 dez 2009.

WORLD HEALTH ORGANIZATION. Collaborating Centre for Research on the Epidemiology of Disasters (CRED). The International Disaster Database. Disponível em: <http://www.em-dat.net>. Acesso em: 4 dez 2011.

WORLD HEALTH ORGANIZATION. Epidemic-prone disease surveillance and response after the tsunami in Aceh Province, Indonesia. Wkly Epidemiol Rec, v. 10, n. 18, p. 160-4, 2005.

WORLD HEALTH ORGANIZATION. Management of dead bodies after disasters: a field manual for first responders. Washington, D.C: PAHO, 2006.

WORLD HEALTH ORGANIZATION. Manejo de cadáveres en situaciones de desastre. Washington, D.C: OPS, 2004.

\section{Notas}

1 T.A.O. Cardoso participou da concepção, pesquisa, metodologia, redação e revisão crítica; M.B.M.A. Navarro participou da pesquisa, metodologia, redação e revisão crítica; F.G. Costa participou da pesquisa, metodologia, redação e revisão crítica. Os três autores aprovaram a versão final do artigo a ser publicada.

${ }^{2}$ A realização deste trabalho contou com o apoio do Conselho Nacional de Desenvolvimento Científico e Tecnológico (CNPq), através do projeto n. 202387/2011-9 (Pós-doutorado no Exterior). 
Biosecurity and disaster: concepts, prevention, public health and management of corpses

The paper discusses the complexity of disasters, enhancing risk situations and the importance of support from Biosecurity, as in episodes with fatalities, procedures formulated by this field should be adopted in the handling of corpses, particularly when occurring with search of buried bodies. It contextualizes the magnitude of the disaster characterized by rain and its aftermath (landslides, burying), emphasizing the phenomenon of global warming and climate change and its impacts on communities, especially the poorest, valuing the concept analysis of vulnerability caused by urbanization, environmental degradation by improper management of natural resources, environmental pollution, inefficient public policies, emphasizing low investment in infrastructure. It emphasizes the concept of disaster as unpredictable, sudden and violent, phenomenon causing numerous deaths and destruction; and social, health, legal and operational problems when there is high number deaths at the same time or within a short time. And it analyzes the contribution of Biosafety as guiding emergency plans facing disasters, enhancing the biological risk and the measures required for handling corpses.

Key words: natural disasters; corpses; biosecurity; exposure to biological agents. 